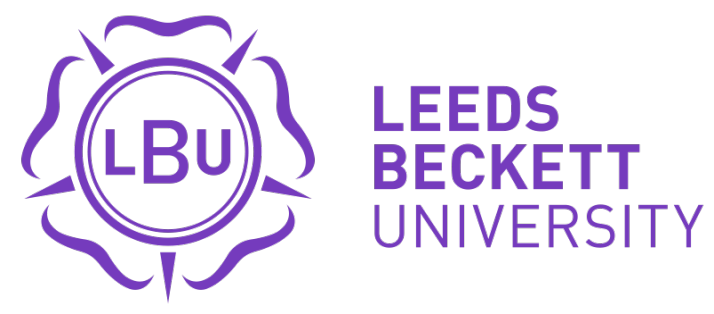

Citation:

Fernandez-Lasa, $U$ and Usabiaga Arruabarrena, $O$ and Lozano-Sufrategui, $L$ and Drew, KJ (2020) Negotiating alternative femininities? Gender identity construction in female Basque pelota players. Sport, Education and Society. ISSN 1357-3322 DOI: https://doi.org/10.1080/13573322.2019.1710699

Link to Leeds Beckett Repository record:

https://eprints.leedsbeckett.ac.uk/id/eprint/6577/

Document Version:

Article (Accepted Version)

The aim of the Leeds Beckett Repository is to provide open access to our research, as required by funder policies and permitted by publishers and copyright law.

The Leeds Beckett repository holds a wide range of publications, each of which has been checked for copyright and the relevant embargo period has been applied by the Research Services team.

We operate on a standard take-down policy. If you are the author or publisher of an output and you would like it removed from the repository, please contact us and we will investigate on a case-by-case basis.

Each thesis in the repository has been cleared where necessary by the author for third party copyright. If you would like a thesis to be removed from the repository or believe there is an issue with copyright, please contact us on openaccess@leedsbeckett.ac.uk and we will investigate on a case-by-case basis. 


\section{Negotiating alternative femininities? Gender identity construction in female Basque pelota players}

Uxue Fernandez-Lasa, Oidui Usabiaga Arruabarrena, Lorena Lozano- Sufrategui \& Kevin J. Drew

\section{ABSTRACT}

The aim of this paper is to explore how female players of Basque pelota (pelotaris) construct their gender identity in a traditionally masculine sport. The theory of performativity is used to understand how females negotiate, resist or challenge the dominant gender discourse. Data were collected through 10 in-depth interviews with players. Through inductive analysis we found that the sociocultural context surrounding Basque pelota reinforces the binary system of gender embodiment, which includes hegemonic masculinities and idealised femininities. However, our findings also suggest that whilst some players adhere to this dominant discourse, others actively resist and transgress it through the embodiment of alternative identities. In doing this, these players create new and inclusive identities, therefore escaping a simplistic binary and embracing a multiplicity of gender identities. As a result, they can become active agents in the promotion of equity in sport.

Introduction

This study explores how women construct their gender identities in a traditionally masculine sport. In particular, it explores: (i) the processes through which women construct their identities; and (ii) whether female players of Basque pelota can resist traditional gendered norms and develop alternative embodiments of femininity in this context.

Sport has traditionally been considered a male arena (Hargreaves, 2000). Often, the values intrinsic to many sports are aligned to the values inherent to androcentrism. This has resulted in the explicit and systematic exclusion of women in most areas of the sporting world (Hartmann-Tews \& Pfister, 2003). Even today, traditional ideas about femininity and masculinity prevail (Hargreaves \& Anderson, 2014). These views are born out of the stereotypes that culture assigns to different sexes, making gender roles socially constructed. In this regard, gender differences are not natural, but acquired and performed, depending on the prevailing social and gender order (Pfister, 2010).

Over the last few decades, there has been a significant shift towards alternative gendered perspectives in sport. This has meant that, whilst female sport has emerged and developed from masculine sport, female sport is now challenging the gender order (Hartmann-Tews \& Pfister, 2003). This is, in part, due to the increased participation of women in sports that were traditionally seen as masculine (Whitson, 2002). These women challenge the way in which females have traditionally been portrayed, demonstrating the dichotomy of a binary gender order.

However, the distinction between what is feminine and masculine cannot be reduced to the simple and radical opposition between men and women (Joncheray, Level, \& Richard, 2016).

Gender hierarchies are no longer simple or binary, but complex and multidimensional (Budgeon, 2014). However, a greater understanding, using intersectionality to analyse the mechanisms through which identities are set and defined within the social order, is still needed (Martin, 2015). 
In addition, sport is a field where gender relationships can be resisted and transformed, through the questioning and subsequent development of social norms (Hargreaves \& Anderson, 2014).

\section{Gender relations in the Basque Country}

The Basque Country is a region between northern Spain and south-western France, and the Autonomous Community of the Basque Country comprises three of its historical territories, including Araba, Bizkaia and Gipuzkoa. The termination of Franco's dictatorship and the implementation of Spanish democracy in 1978 marked a change in the position women occupied in Basque society, and there- fore the historical structure of the gender order (Amurrio \& Esteban, 2010). The Basque Women's Insti- tute was founded in 1988. Since then, women's involvement in employment, politics and public life has significantly increased (Amurrio \& Esteban, 2010). Whilst these improvements are promising, there is still a gender gap. To illustrate, gender inequalities are evident in economy, working con- ditions, financial independence and the distribution of time dedicated to domestic work, where women are still worse off than men (Novo \& Elizondo, 2010). Additionally, some areas such as power and social prestige are male-dominated (Díez Mintegui \& Bullen, 2010). Similarly, there are still profound symbolic barriers for women to participate in traditional celebrations and folklore. The combination of a conservative standpoint with androcentric gender relationships has resulted in the impossibility for women to participate in the central acts of some festivals (Díez Mintegui \& Bullen, 2010). These inequities are 'preventing women from becoming protagonists in the context of Basque cultural representation, since the hegemonic role in the Basque square, the public space par excellence, is flatly masculine' (González, 2013). In summary, despite some improvements, gender inequalities against women still exist in the Basque Country.

Sport in the Basque Country

Sport is a microcosm of Basque society. Social and cultural stereotypes continue to generate inequality with regards to women's participation in sport. To illustrate this, women represent only $21.01 \%$ of all sports registered players in the Basque Country, and out of 47 sports federations, only one of these is chaired by a woman. Furthermore, only $15.66 \%$ of the members of the governing boards were women in 2015 (Department of Education, Linguistic Policy and Culture of the Basque Government, 2016).

With regards to the sports that have strong cultural roots in the Basque Country (i.e. rowing and rural sports), only $20.3 \%$ and $11.89 \%$ are women, respectively. What is worse, women's participation in Basque pelota is even lower, with only $7.04 \%$ of associated athletes being women (Direction of Youth and Sports of the Basque Government, 2017). These statistics are clearly showing inequitable access to sport, in particular to sports modalities that are part of the Basque culture and folklore, where women continue to experience direct and indirect discrimination when attempting to participate in.

A cultural and gendered history of Basque pelota

Basque Pelota is a deeply rooted traditional sport in the Basque Country. It is one of the oldest and most traditional sports in the region. Basque Pelota originated from the medieval jeu de paume (palm game), and it is one type of sport within the category of ball games, including thirty different 
types of games. The most common type of game is hand ball (pelota a mano), which is played only by men and accounts for about $50 \%$ of registered Basque pelota players (Fernandez-Lasa, Usabiaga, Martos- García, \& Castellano, 2015). Like other culturally relevant sports, Basque pelota is identified and perceived as masculine. As González (2012) concluded 'being born as a pelota player implies being a male'. Basque pelota represents many values related to Basque identity, such as strength, resistance and nobility. These traits have been traditionally associated to hegemonic masculinity, being against the cultural ideal of femininity and being unimaginable that women would ever become pelota players (González, 2013).

The idea of women occupying the central space of Basque pelota - the fronton (court) - is incompatible with the cultural image of the Basque country, where women are excluded from undertaking any leading roles in sports (González, 2013). However, despite Basque pelota been considered a mas- culine domain, there were and there currently are female players. From a historical perspective, raquetistas (female pelota players who used a wooden racquet and a leather ball) were the pioneers, until the end of twentieth century. Notwithstanding, raquetistas were thought to fail to comply with the emphasised femininity at the time, and this caused resistances in gender relations. As a result of this, and driven by the Francoist regime, raquetistas were excluded from structured organisations and their sport ceased to exist (Urrutia \& Sagastizabal, 2009).

In the present-day there are pelota federations, licenses and championships for women in all Basque territories and also internationally. Female pelotaris can now participate in official calendar competitions in two modalities: the first one is called paleta goma and involves playing pelota with a racket bat and a rubber ball in a short fronton. The other one is Argentinian paleta. However, only a minority of females partake in either of these specialities (Fernandez-Lasa et al., 2015).

\section{Gender identity construction in sport}

Gender socialisation occurs when individuals adopt attitudes and modes of thinking, behaving and feeling that are aligned with a socially assigned gender identity (Joncheray et al., 2016). Identity construction is a complex and dynamic process, diverse and fluid, including several dimensions (Thorpe, 2010). It can also be readjusted as a result of changes in political, social and cultural factors (Hargreaves \& Anderson, 2014). When gender is understood as a binary system, individuals' ability to negotiate what their gender means to them is impaired, and this limits their ability to challenge traditional gender roles. Therefore, embodied representations should enable individuals to repurpose, recreate or rebuild their sense of gender identity. This process of identity negotiation should be expressed on a continuum, where individuals can position themselves in its different parts at different times (Budgeon, 2014; Martin, 2015). In this regard, masculinity and femininity are represented through the embodied individual, and such embodiment takes place in specific social contexts. Historically, these contexts have privileged masculinity over femininity, but they have also privileged specific ways of being a man or a woman (Whitson, 2002).

The traditional limits posed on femininity and masculinity can be transgressed through the prac- tice of sport (Scraton \& Flintoff, 2002). Sport is a social field where gender socialisation gains significance (Messner, McKay, \& Sabo, 2000). Metaphorically, sporting practice can be seen like a sanctuary where traditional femininities and masculinities are reinforced, and the dominance of physical culture in modern industrial societies has contributed to this (Thorpe, 2009). This can explain why dominant ideas about gender and sexuality are strongly ingrained in sporting contexts, 
and transgressing them is almost impossible (Ratna, 2014). Through the practice of sport, men can embody hegemonic ideals that are seen to represent the broader society, and women are sexually objectified by the hegemonic male (von der Lippe, 2013). Most sporting spaces have become a male sphere, which is gendered through heteronormative creations (Tredway, 2018). Thus, the participation in physical activity and sport can contribute to the development and embodiment of gendered behaviours and norms. In the context of physical education, heteronormativity limits the opportunities that are available for young people to transgress (Metcalfe, 2018). In turn, such experiences have contributed to the nor- malisation of gender stereotypes, such as masculine strength and feminine weakness. Notwithstand- ing these normalisations, the construction of alternative cultural contexts has enabled new ways of being a man or a woman - it is in these contexts that individuals feel empowered to escape the binary system and embody their own forms of masculinity or femininity. Thus, it is important to use sports and physical practices as tools that can help promote gender embodiments beyond patri- archy (Whitson, 2002).

Women's participation in sport is intrinsically linked to their sense of identity and subsequent sense of belonging in certain sporting contexts. To be able to participate in sports, many women have had to negotiate dominant ideas and structures - a process that, in its own right, has shaped their identities (Hargreaves, 2000). Managing their identities has enabled sportswomen to feel included, and empowered them to deal with discrimination and social exclusion in their sports (Ratna, 2014). However, identity management becomes more difficult for women when they are involved in sports that are traditionally seen as masculine or historically male-dominated terrains (DiCarlo, 2015). Thus, female sport can be used to challenge patriarchy and empower women through policy, culture and society (Hargreaves, 2000). The use of images of women that challenge traditional gender stereotypes can provide spaces of resistance and empowerment for women, which in turn can be understood as (re)constructions of physicality (Hardy, 2015).

Identity construction in traditionally male sports is influenced by social norms, due to the cultural tension that arises from traditional femininity and sportswomanship (DiCarlo, 2015). Consequently, women's involvement in these sports involves the negotiation of space and power (Bäckström, 2013). Attitudes of resistance could be materialised in one of two ways: (i) through the defiance and transformation of emphasised femininity; or (ii) through female apologetic behaviour, enacted within certain boundaries in response to negative stereotypes associated with female involvement in sport (Hardy, 2015; Jeanes, 2011; Knijnik, 2014). Several studies have concluded that women can undergo both submission and autonomy in their lived experiences (Bäckström, 2013; Jeanes, 2011; Thorpe, 2009). Even though sportswomen can - and often do - challenge emphasised femininity, they do this within certain boundaries. For example, with regards to building muscle, women know how much of it is socially acceptable in a way that does not compromise their attractiveness as heterosexual females (Dworkin \& Messner, 2002). As such, women who transgress traditional gender roles are accused of masculinisation, suspected of homosexuality, discriminated against, and/or refused legitimacy. Therefore, it is not surprising to see many sportswomen experiencing a crisis of gender identity when participating in traditionally male dominated sports (Joncheray et al., 2016; Knijnik, 2014). However, partaking in these types of sports can present opportunities for women to redefine and celebrate their participation on their own terms, instead of in comparison to, or in the shadows projected by men (Broad, 2001; Hardy, 2015; Thorpe, 2009). However, many female athletes still feel restricted in the way they use their bodies whilst participating in sport. This is because they avoid moving and behaving in ways that may be seen as alternative represen- tations of femininity (Jeanes, 2011). Furthermore, when sporting action is framed with a dominant gender identity it makes sense to attribute masculinity to men and femininity to women. Instead, sporting actions that challenge traditional gender notions are 
considered anti-natural (Wesely, 2001). Sportswomen who do not perform femininity and do not fit within their prescribed gender actively challenge gender expectations through their physical skill and power (Tredway, 2018). Thus, in sport, gender relations and power are reproduced and transformed. Hence, sport is a para- doxical social arena where sexism and equal opportunities can occur simultaneously (Hargreaves \& Anderson, 2014).

\section{Embodiment of alternative femininities}

When it comes to the embodiment of femininity and transforming a feminine gender identity, different possibilities of active negotiation are possible. These are based on the acceptance or resistance towards the way in which women are embodied (Hardy, 2015; Jeanes, 2011). McNaughton (2012) explored how women in combat sport violated conventional womanliness by foregrounding physical capability and aggression. By connecting a critical look at gender and sport, she rewrote conceptions of womanhood and claimed for more flexible frameworks and cultural constructions of gender. For Bäckström (2013), active femininities are disruptive, because they do not represent a complementary relationship to patriarchal domination and/or subordination between women and men. However, following Budgeon (2014), there are some new femininities, overcoming traditional femininity, that delimit the boundaries of socially acceptable femininity. These new femininities are organised in a hierarchy according to their construction and representation. Thorpe (2009) suggests that different forms of femininity are legitimised based on the positioning of females and the gender relations that occur in a given context.

In a study with female rugby players, Hardy (2015) concluded that in defiance of having been stigmatised for looking masculine and unattractive, participants resisted and redefined the traditional version of femininity by demonstrating that they could also be fit, muscular and beautiful. Furthermore, instead of engaging in female apologetic behaviour, participants stepped outside their accepted gender performance, assuming to be outside the normative bounds. Rugby gave those women a safe space where they performed an accepted resistant version of femininity that they con- tinued to perform outside the sports arena, pushing the boundaries of what is (seen as) feminine (Hardy, 2015).

Davies and Deckert (2018) explored how female fighters challenged conventional notions of femininity, and concluded that they subverted, reinvented and also reinforced feminine norms. They actively reconfigured the limits by becoming themselves feminine fighters, repositioning women's participation in the sport. Symbols of strength and power were no longer masculine attributes, but they emerged as a desired feminine norm. They became role models for a wider audience, especially for young girls.

Following several studies exploring the performance of femininities, Ussher (1997) put forward four categories: 'being girl', 'doing girl', 'resisting girl' and 'subverting girl'. The first category, 'being girl', related to the archetypal position of women, who prefer to be a woman before 'doing' femininity, thus fostering traditional femininity. In the second category, 'doing girl', Ussher represented femininity as a 'female costume', or the knowing that femininity can be performed as part of the sporting context. Thus, these women were able to change between looking like a woman and ridicule the performance of femininity during sports, but not outside. Women grouped in the third category, 'resisting girl', denied facets of traditional femininity, such as the need to maintain a disciplined body or the embodiment of archetypal beauty. The fourth category, 'subverting girl', was related to women who intentionally used their gender to publicly subvert tra- 
ditional femininity. These representations capture the complexity of the continuous processes of gender negotiation and resistance that women may experience temporally. The above categories are not fixed, but dynamic and fluid, and illustrate the different gender positions that women may adopt at different stages of their lives. More recently, Pope (2014), informed by Ussher's work, analysed the performance of female football fans, proposing two categories: 'masculine' femininities and 'feminine' femininities. The former category featured resistance, and depicted features related to masculinity. Contrary to this, the latter emphasised traditional femininity.

Likewise, Jeanes (2011) suggested four categories to represent dominant femininities in football, including (1) 'girlie', (2) 'tomboy', (3) 'sporty' and (4) 'popular'. The first category was identified as 'girlie', which related to sportswomen who acted within the boundaries of idealised femininity. The second category was called 'tomboy' and referred to women who enjoyed active play during leisure time in ways in contravention to idealised femininity. Women's engagement in leisure activities in this way was thought to symbolise men, even though women did not necessarily intend or want to look like men. The third category was that of 'sporty', and it was meant to represent women who were skilled at sports, which alleviated them to a higher status in their sporting context. The last category was identified as 'popular' and alluded to women who were both sporty and girlie - they were good at sports, but they also engaged in feminine behaviours such as putting on makeup, going out with boys and gossip.

Despite her proposal of feminine categories, Jeanes (2011) concluded that women in general tend to be resistant to challenge and transform their notion of traditional femininity. Similarly, Azzarito (2010) added the concept of hybrid bodies, which represent two different and alternative femininties and include 'alfa girls' and 'girls of the future'. These two representations resisted and redefined the traditional non-sporty female body, which was portrayed as thin and restricted. By representing female physicality in positive ways - i.e. powerful, healthy and fit - Azzarito's work challenges the traditional embodiment of the female body as docile and aims to empower girls in the process of identity construction.

Furthermore, Bäckström (2013) explored the most dominant femininities amongst skateboarders, and identified three types: the 'tomboy', the 'bitch' and the 'lesbian'. In Bäckström's study, 'tomboys' perceived male skateboarding as positive, and practiced with them in pursuit of their approval. 'Bitches' claimed their authority by negotiating the social and cultural ways of being a woman and by rewriting the rules. However, 'lesbians' had an honest and open attitude towards homosexuality and bisexuality. They presented a more stereotypical position, characterised by independence and aggression, and were stigmatised for this.

\section{Theoretical framework}

The theoretical framework underpinning this study is based on the principles drawn from poststructuralist feminism. Specifically, it focuses on Butler's (1990) theory of performativity of gender, where gender identity is understood as multiple, fluid and dynamic. This means that gender is a social construct that is (re)produced through the body in cultural contexts. Although dominant discourses are often set up as 'natural'- hence establishing a heterosexual framework through the matrix of normative gender relations that influences the enactment of femininity - Butler's work offers the opportunity to challenge and change this reality through the application of alternative performative acts, embody- ing multiple femininities. Gender is performatively constituted, bringing particular kinds of realities disputing if there is a stable gender in place and intact prior to the expressions and 
activities that we understand as gendered expressions and activities. These acts, in turn, are influenced by the restric- tions imposed by the dominant norms. The gender performance is closely related to the reproduction of traditional gender roles and identities. However, it is possible to represent those alternative acts through individual action. Notwithstanding, this agency is restricted by dominant discourses and existing power regimes. As a result, this is a risky process for those women who defy normative gender relations, because they may face accusations of not being real or normal women (Butler, 1990). As a critique to Butler's theory, Schep (2012) suggested that, paradoxically, challenging reiterated and essentialist notions of gender and sexuality, and constructing a paradigm which could extend the range of possible gender identities, Butler made some gender expressions impossible. He perceived some problems concerning the hegemonic framework of Butler's theory within the field of gender studies, as it is based on universal validity, avoiding the need for thinking openness which is not found in Butler's work. Nonetheless, he concluded that thinking in its limits, this theory makes pro- gress in gender theory, being aware of the possibility to lead to a less exclusionary way of conceptualising gender (Schep, 2012).

Butler's theory has been applied in sports literature to understand the experiences of female athletes. Writing about athletic bodies and women's sports, Butler (1998) concluded that many sportswomen with athletic bodies, such as Martina Navratilova, challenged gender ideals and traditional standards. In doing this, they inevitably came into conflict with certain ideal feminine morphologies, hence causing a crisis in the category of women, and destabilising gender norms (Butler, 1998). Therefore, female athleticism has the potential to contest normative and binary understandings of gender, as gender performativity informs and becomes a part of the sexed body (Tredway, 2018).

With these thoughts in mind, the aim of this study is to analyse the strategies female pelotaris use in the process of construction and maintenance of their gender identity, putting forward typologies that arise. In doing this, this study will aim to answer the following research questions: (a) Why did women start to play Basque Pelota and how did they experience this process? (b) How do female pelo- taris embody their gender identity and its relationship with the traditional notion of femininity? (c) How do female pelotaris carry out the process of changing the dominant gender norms through their agency, and how do they construct different femininities? In answering these questions, this study will contribute to the existing literature on women's experiences of participating in traditionally male sports. It will also add important insights to the body of literature on negotiating gender. Additionally, Basque Pelota con- stitutes one of the main disciplines within Basque physical culture, yet it remains understudied. This paper will contribute important knowledge about how beliefs and ideologies influence the binary per-formace of gender identity within the Basque culture. Thus, this study not only offers new perspectives on female identities, their interactions, fluctuations and how these are represented, but it also adds to the debate about how social realities can be transformed from a gender perspective, without limiting only to the reproduction of the dominant traditional notions of hegemonic masculinity and emphasised femininity. In conclusion, this study seeks to understand if - and if so, how - Basque Pelota, like other traditionally masculine sports, could contribute to the resistance and change of gender norms, therefore providing female pelotaris with a space to represent counter-femininities.

\section{Methods}

This study is underpinned by a constructivism, and qualitative research. We conducted semistructured interviews with 10 female pelotaris, aged 22-45. Criterion-based sampling was applied, whereby, pelotaris had to either hold a current licence to compete, or had held a licence previously, 
and were not currently competing. We included at least one player from each territory within the Basque Country. Initial contact with participants was carried out through the territorial federations of Basque Pelota. Further purposeful sampling followed, where a snowball sampling technique was used to recruit further pelotaris.

Data collection was conducted by the first author (UF) and ceased when the research team agreed that data saturation had been reached. UF is a former female pelota player, she was 27 years old at the time of this study, with an experience of five years playing high level championships. Thisfacilitated the process of building trust and rapport with participants. We completed an interview with each participant where pelotaris were invited to talk about their beliefs and ideologies about their identity. We also kept a field diary, where we noted down observations during each interview.

The process of data analysis was inductive. Interviews were transcribed verbatim, coded and analysed with the aim of identifying emerging themes, which included: (i) women's entry to Basque pelota; (ii) identity construction; and (iii) alternative femininities, transformation of the traditional notion of femininity. We gave participants a verbatim transcript of their interview, for the purposes of member checking. This process was meant to strengthen the credibility and trustworthiness of this research (Fetterman, 1998). Both the researchers and two participants analysed the reports generated during this process, therefore allowing for critical opinion and member checking, according to the credibility criteria set out by Sparkes and Partington (2003). The software ATLAS.ti 6.2 (Friese, 2012) was used to support data analysis.

Results and discussion

Results are presented under the following headings: (a) Female pelotaris' entry to the sport; (b) Constructing gender identities and (c) Creating alternative femininities.

Female pelotaris' entry to the sport

Several participants talked about feeling 'different' when they started playing the sport, because they were surrounded by males and female presence was conspicuous by its absence. Many participants talked about feeling isolated, as Saioa explained:

I've always played with boys. I felt like the only girl on an island. It was weird not to see other girls playing pelota. I thought, 'I can't be that odd!'.

Likewise, many participants felt that pelota was a masculine sport, particularly those who started to play during childhood. For example, Nekane's experience was particularly hard and hurtful. She was forced to stop playing pelota due to the social pressure her father experienced, as others propositioned that pelota was not an appropriate sport for his daughter:

I had to stop playing when I was 14 , I was forced to stop. People started to say to my dad: 'Well, Nekane is now developing to become a woman, or she may have already developed, she is a woman'. So I used to say: 'but, why should I stop playing? I don't want to stop'. 'No, you are a girl, you are out'. How nice of them! Because they were bothering my dad with that, he came and told me: 'Right, I am going to buy you an accor- dion, ok?' So, he bought me an accordion and I left it there. I had a horrible time. I wanted to play pelota, I didn't understand why I had to stop. I kind of came to terms with it over time, and I still used 
to play pelota in the village, I've never lost contact with the fronton. I played with everyone I wanted to, but I did not take part in competitions.

These initial and discriminatory experiences, in which pelota is clearly portrayed as a male sport, determine women's construction of their gender identity, given its complexity. The adjustment or lack of it - to the interpretations of the social archetype, and the lack of social support - even from loved ones - cause contradictory and negative feelings. These are a result of the lack of acknowl- edgement and acceptance with regards to social norms.

Previous authors have described similar experiences amongst women participating in other sports, such as football, combat sports or rugby (Davies \& Deckert, 2018; DiCarlo, 2015; Jeanes, 2011; Joncheray et al., 2016; McNaughton, 2012). They highlighted that masculine culture was the most important characteristic of certain sports. This also occurs in the Basque context, given that Basque Pelota gives prestige and recognition to male professional players (González, 2012). Thus, pelota is clearly a masculine sport and those women who wish to practice it are likely to be discrimi- nated against (González, 2013).

\section{Constructing gender identities}

Whilst constructing their gender identity, participants talked about the need of defining and situating themselves as a particular type of woman, i.e. the need of knowing 'who' they were. This interpret- ation was made in relation to pelota and their positioning with regards to a binary gender system. In doing this, they found resistances and contradictions related to the social archetype, which came from their internal and external conflicts. These had a direct influence on how participants behaved and defined themselves.

When embodiments of femininity and social norms do not match, certain attitudes and bodily images are labelled negatively by social agents, such as family, female friends and the media. Breach- ing social and gender norms comes at a cost (With-Nielsen \& Pfister, 2011). Participants identified labels like 'tomboys' as a stereotype that was associated with them. They talked about becoming targets of stigma as a result of their participation in a sport that is not common amongst females. Nora talked about this: 'Some people see Basque pelota as a sport for men. They think that you have to be a bit brute, a bit of a tomboy'.

However, with regards to the term 'tomboy', participants showed differences in what it meant to them. For example, for Eider to be a tomboy was natural, she referred to herself as a 'tomboy', based on how she behaved and her attitude towards girls who did not like sport:

I have always been a tomboy. Pelota was another sport. Nobody said anything to me about playing pelota. Everybody knew me in my village and they knew that I always used to play with the boys. We spent hours playing, and as I consider myself as someone quite skillful, I was quite good, compared to others. I played, but nobody said anything to me about it, it was normal for my family and my mum has always supported me. I was a tomboy, and I always had a ball from the age of 4 or 5 . Girls didn't say anything to me either. They did their own thing.

Eider's close social environment did not stop her from becoming a pelotari. Being skilful gave her social recognition and acceptance. Although she knew that ball sports were associated with boys, 
she did not have any problems with other girls. She was proud to admit that she was different from the other girls and, in doing this, she remained resistant to normative femininity.

In contrast to Eider, Zuriñe talked about the stigma of being labelled a 'tomboy', which was something she did not identify herself with. She acted in the ways society expects a girl to behave: 'During that time, you would have breached the rules, you had to be feminine, it wasn't socially acceptable not to be'.

Many participants talked about their situation becoming normalised when they changed groups and started to play with other females in the format of pelota called paleta goma. Here, they had federative rights and could take part in official competitions. All players were female and felt welcome to the sport:

When I stopped playing pelota a mano and I started playing paleta goma, as we were all girls, then my relation- ships with others became normal. I was just another girl. The situation was more normalized, it was different from playing with boys.

Although this process of normalisation was evident in this study, this finding contrasts with similar studies done in other sports. To illustrate, Jeanes (2011) found that in football, peers had an influence on limiting the appearance of alternative femininities, to the extent that some players were left aside. Additionally, females have also experienced stigmatisation in other sports such as hockey, and also in PE, which made participation difficult for them (DiCarlo, 2015; Metcalfe, 2018; With-Nielsen \& Pfister, 2011). In contrast, when playing with other females, pelotaris feel comfortable participating in a sport that is appropriate for them, enabling them to escape from stigmatisation (Dashper, 2016; Hardy, 2015; Macro, Viveiros, \& Cipriano, 2009).

According to our findings, in Basque pelota there are different ways of acting with regards to the gender order established in the social imaginary. For example, whilst Eider chose to perform unconventional femininity, Zuriñe instead embodied her femininity within the limits set out in society. This illustrates multiple and different constructions of pelotaris' identities and their relationship with traditional femininity.

This finding resonates with the studies by Davies and Deckert (2018), Hardy (2015) and Joncheray et al. (2016), who found different identities amongst sportswomen, some of whom decided to challenge and transgress traditional femininity. However, others opted to promote traditional or alternative femininities, but only within the sports field (DiCarlo, 2015; Jeanes, 2011). With this thought in mind, we argue that sports can be a means to assume or transform gender power relations (Hargreaves \& Anderson, 2014).

Creating alternative femininities

During the process of identity construction, some pelotaris resist the gender order and the notion of traditional femininity through gender negotiation. These women construct and interpret alternative femininities outside the binary system, therefore breaking the barriers posed by traditional femininity and hegemonic masculinity (Tredway, 2018; Wesely, 2001).

Through their actions, some pelotaris highlighted the need of accepting everyone as they are, without prejudice or stigmatisation. Similar to this, McNaughton (2012) reinforced the need to embody non-traditional identities without stigmatising those who resist traditional femininity. 
By doing this, the stereotypes that could limit their actions and decisions were put to one side. Broad (2001) suggested that women who play sports that have been traditionally seen as masculine have an opportunity to resist social norms and gender order through their own participation in the sport. Nekane supports this idea, when she talked about the need of escaping from stereotypes and empowering females to play sport on their terms, particularly at young ages. She said:

I hope that young girls will have a much smoother path than we have had. I hope that, from the moment they want, and if they are given a ball, they will be able to take part in competitions, like boys do, I hope their participation will be seen as acceptable, and I hope nobody will say that they are tomboys. You are a girl, and you are as feminine or even more than any other girl. People are different. Some people give their opinions, instead of letting the girls have an opinion. They say: 'No, no, she can't play pala, she is going to have big shoulders!' People say nonsense, don't they? What about handball players? Don't they develop big shoulders? And what about swimmers? Do you want to play sport or not? Then, what they should do is let the girls choose, let them play whatever sport they want, and this should not be frowned upon. We, as women, should be allowed to do whatever we want to, and nobody should put up any barriers for us to do so.

Nekane's reflection suggests that playing pelota should not have a negative influence on female pelotaris' identity construction. Accordingly, Butler (1998) concluded that through their athletic bodies, which depicted muscularity and strength, some women destabilised traditional gender norms. In her previous statement, Nekane refers to how gender stereotypes can sometimes limit girls' sense of freedom to partake in sports of their choices and desires, mostly when these do not match the normative gender order in society and the heterosexual framework. Furthermore, Nekane highlights the importance of letting girls choose for themselves, without anybody negatively influencing their decisions. Her surrounding social environment forced her to stop playing pelota when she was young, because it was not seen as a sport that was appropriate for her as a teenager. However, during adulthood, nobody objected to her playing again, and her mum showed unconditional support. At 40 years of age, Nekane continues playing at high level, although she was forced to stop competing for three years in her adolescence:

I stopped playing when I was 15 . Then they rang me when I was 18 . They rang the land line at my parents' house, and my mum answered the phone, and without asking anything to anyone, she said to them: 'When did you say you are coming, Saturday? She will be here on the dot'. So she rang me and I was in Pamplona, and she said: 'Nekane, they've called from Estella, and they are going to come here to do a test to see if you can play pala again'. I was very nervous. I was there on Saturday, and I couldn't wait for them to arrive. So that's when I started again, and I am still here. I've been here since then.

Players like Nekane, as well as Eider, perform within a strategy of collective resistance, transgressing gender boundaries and embodying alternative femininities. Through their athletic competence and physical power, sportswomen can challenge socially expected gender expressions and become activists of more inclusive identities (Tredway, 2018). Like the female skateborders in Bäckström's (2013) study, they emphasise the dignity of what they do, including the improvement of their sporting skills, by virtue of the friendships and sense of belonging they have in their sport. These positive social relationships are key to facilitate the development of alternative femininities. Likewise, Fernandez- Lasa et al. (2015) highlighted the importance of creating relational networks; these networks would allow pelotaris to feel comfortable in this space, support and encourage resistance and a col- lective escaping from normative stereotypes. 
The analysis of pelotaris' strategies of resistance and the processes through which they construct their identities has yielded the following typologies with regards to traditional femininity. To do this, we use Ussher's (1997), Jeanes' (2011), Bäckström's (2013) and Pope's (2014) studies as reference points. This proposal is presented in the form of a continuum, given that identities are diverse, dynamic and fluid, and can change according to changing political, social and cultural climates (Hargreaves, 2000; Joncheray et al., 2016). In doing this, we aim to move away from the binary gender system and, at the same time, with traditional concepts regarding gender, as gender identities are developed in broader contexts (Butler, 1990; Thorpe, 2009).

The continuum that is presented below is divided into the four most representative categories of pelotaris' femininities. These categories have been drawn from the existing literature, as well as the interview data of this study and the first author's experiences and observations in the sport context. They analyse the skill level of the sportswomen, their attitudes and way of expressing emotions in the fronton, and the way in which they perform their gender identity. It is important to highlight here that the position participants occupy in this continuum is context-dependant, so female pelotaris may move across different categories at different time points.

- 'Masculine femininity': these players have a high level of skill and are very competitive. They like standing out, they are passionate, and some of them are often loud. They are also expressive and often swear, showing a rebellious attitude. They transform traditional femininity and contradict the discourse of docile femininity. They show characteristics associated to masculinity, but they do not want to look like men, even though society often categorises them as such.

- 'Sporty': they have high levels of ability and they like competing. They have a high status due to their level of ability. Their performance in the court stands out, but they are less rebellious and have more self-control than those from the 'masculine femininity' category. Sporty women transform traditional femininity due to their sporting skills, hence challenging the gender order.

- 'Popular': they are good at sports, and they compete at a good standard, but they do not like standing out. They show several of the characteristics often assigned to women and emphasised femininity during the game: they put make up on and they wear jewellery. Somehow, they transform traditional femininity but only when playing sport. They display an apologetic behaviour outside of sport.

- 'Girlie femininity': their level of skill is average, and they are less competitive. They play without transforming their body image. They meet all the canons conferred to women in idealised femi- ninity. They define their identity within the boundaries of traditional notions of masculinity and femininity.

Through the creation of inclusive identities such as alternative femininities and by resisting the binary gender system, several participants are agents of change in their environments. In this way, they challenge and transform power and gender order relations. These attitudes of resistance and action increase sportswomen's sense of empowerment and enrich their lives (Dashper, 2016; Hargreaves, 2000). Playing pelota can liberate women but, at the same time, their involvement in the sport is influenced by the discursive practices of gender difference and the embodiment of emphasised femininity. This may sustain the hierarchy of gender structuring (Bäckström, 2013; DiCarlo, 2015). 


\section{Conclusion}

For gender equity to be achieved, gender relations and identities must be redefined. Gender stereotypes influence the process of identity construction amongst sportswomen, and Basque pelota is still a space for men in the social imaginary of the Basque culture. This directly influences the strategies used by sportswomen in the process of identity creation. However, to overcome such discrimination and obstacles and break habits, several female pelotaris act to revert the status quo. They do so by creating alternative femininities and breaking with the dichotomy of masculine and feminine. In this context, sport is used as a tool to challenge gender relations. Nevertheless, not all sportswomen behave in this way, and some still embody their identity within the traditional notions of gender.

This study has contributed to developing an understanding about how traditional ideas about gender influence the process of negotiation and identification of gender identities amongst women who take part in sports that have strong cultural roots. In doing this, this study also adds to the literature about women's experiences of playing sports that are traditionally seen as masculine. In this context, it is fundamental to represent the fluidity of gender identities on a continuum, where sportswomen can position themselves in different parts of it at different times. Acknowledging that gender identity is fluid and dynamic, as opposed to static and constant, helps to clarify the limitations the dichotomisation of gender poses on the process of identity construction. The embodiment of new alternative identities could facilitate a change in the social imaginary and help advance the transformation of social reality. In turn, the maintenance and embodiment of traditional femininities could slow down the transformation of gender relations.

During the continuous process of change and restructuration of gender relations, it is important that sportswomen themselves lead this transformational process through their own empowerment, promoting different identities, creating new femininities, and seeing diversity as something enriching. This would contribute to women obtaining new wider and more inclusive social spaces.

This study is not free from limitations. Given the nature of this study, we were not able to explore how the embodiment of identity changes over time amongst female pelotaris. Furthermore, it would have been interesting to explore the experiences of women who start their sporting career before they reach adulthood. In doing this, we could have understood how adolescence may influence the embodiment of gender identity and its tensions with regards to the conventional gender order established within society. Therefore, future research could use longitudinal designs to understand how sportswomen's identities develop over time, and to explore how they move across the proposed continuum, from the moment they enter the sport through to elite. Additionally, it would be useful to undertake this study in other traditional sports in the Basque Country, such as rowing and other rural sports, to understand how the Basque identity and the imaginary of this society develops as we move forwards in the journey towards equity.

\section{Disclosure statement}

No potential conflict of interest was reported by the authors. 


\section{References}

Amurrio, M., \& Esteban, M. L. (2010). Introduction. In M. L. Esteban \& M. Amurrio (Eds.), Feminist challenges in the social sciences. Gender studies in the Basque Country (pp. 7-10). Reno: Center for Basque Studies and University of the Basque Country UPV/EHU.

Azzarito, L. (2010). Future girls, transcendent femininities and new pedagogies: Toward girls' hybrid bodies? Sport, Education and Society, 15(3), 261-275.

Bäckström, A. (2013). Gender manoeuvring in Swedish skateboarding: Negotiations of femininities and the hierarchical gender structure. Young, 21(1), 29-53.

Broad, K. L. (2001). The gendered unapologetic: Queer resistance in women's sport. Sociology of Sport Journal, 18(2), 181- 204.

Budgeon, S. (2014). The dynamics of gender hegemony: Femininities, masculinities and social change. Sociology, 48(2), 317-334.

Butler, J. (1990). Gender trouble. Feminism and the subversion of identity. London: Routledge.

Butler, J. (1998). Athletic genders: Hyperbolic instance and/or the overcoming of sexual binarism. Standford Humanities Review, 6(2), 103-111.

Dashper, K. (2016). Strong, active women: (Re)doing rural femininity through equestrian sport and leisure. Ethnography, 17(3), 350-368.

Davies, S., \& Deckert, A. (2018). Muay Thai: Women, fighting, femininity. International Review for the Sociology of Sport, doi:10.1177/1012690218801300

Department of Education, Linguistic Policy and Culture of the Basque Government. (2016). Working on equality in Basque sports federations: Guiding reflection to take action. Vitoria-Gasteiz: Central Publications Service of the Basque Government.

DiCarlo, D. (2015). Playing like a girl? The negotiation of gender and sexual identity among female ice hockey athletes on male teams. Sport in Society, 19(8-9), 1363-1373.

Díez Mintegui, C., \& Bullen, M. (2010). Matriarchy versus equality: From Mari to feminist demands. In M. L. Esteban \& M. Amurrio (Eds.), Feminist challenges in the social sciences. Gender studies in the Basque Country (pp. 113-126). Reno: Center for Basque Studies and University of the Basque Country UPV/EHU.

Direction of Youth and Sports of the Basque Government. (2017). Evolution of the number of federated sports women. License history 2012-2016. Retrieved from https://www.euskadi.eus/web01-a2kirola/es/contenidos/informacion/ berdintasuna_estatistikak/es_es/index.shtml

Dworkin, S. L., \& Messner, M. A. (2002). Just do ... what? Sport, bodies, gender. In S. Scraton \& A. Flintoff (Eds.), Gender and sport: A reader (pp. 17-29). London: Routledge.

Fernandez-Lasa, U., Usabiaga, O., Martos-García, D., \& Castellano, J. (2015). Creating and maintaining social networks: Women's participation in Basque pilota. RICYDE. Revista internacional de ciencias del deporte, 40(11), 129-144.

Fetterman, D. M. (1998). Ethnography. In L. Bickman \& D. J. Rog (Eds.), Handbook of applied social research methods (pp. 
473-504). Thousand Oaks, CA: Sage.

Friese, S. (2012). Qualitative data analysis with ATLAS.ti. London: Sage.

González, O. (2012). Basque pelota: A ritual, an aesthetic. Reno: Center for Basque Studies. González, O. (2013). Displaced bodies: Gender, sport, and cultural domination in the Basque court. Revista de Antropología

Iberoamericana, 08(1), 83-110.

Hardy, E. (2015). The female 'apologetic' behaviour within Canadian women's rugby: Athlete perceptions and media influ- ences. Sport in Society, 18(2), 155-167.

Hargreaves, J. (2000). Heroines of sport: The politics of difference and identity. Londres: Routledge. Hargreaves, J., \& Anderson, E. (2014). Routledge handbook of sport, gender and sexuality. London: Routledge.

Hartmann-Tews, I., \& Pfister, G. (2003). Women's inclusion in sport - international and comparative findings. In I. Hartmann-Tews \& G. Pfister (Eds.), Sport and women - social issues in international perspective (pp. 266-280). London: Routledge.

Jeanes, R. (2011). 'I'm into high heels and make up but I still love football': Exploring gender identity and football partici- pation with preadolescent girls. Soccer \& Society, 12(3), 402-420.

Joncheray, H., Level, M., \& Richard, R. (2016). Identity socialization and construction within the French national rugby union women's team. International Review for the Sociology of Sport, 51(2), 162-177.

Knijnik, J. (2014). Gendered barriers to Brazilian female football: Twentieth century legacies. In J. Hargreaves \& E. Anderson (Eds.), Routledge handbook of sport, gender and sexuality (pp. 121-128). London: Routledge.

Macro, E., Viveiros, J., \& Cipriano, N. (2009). Wrestling with identity: An exploration of female wrestlers' perceptions.

Women in Sport and Physical Activity Journal, 18(1), 42-53.

Martin, M. (2015). Assessing the sociology of sport: On gender identities in motion and how to deessentialize difference (s). International Review for the Sociology of Sport, 50(4-5), 542-546.

McNaughton, M. J. (2012). Insurrectionary womanliness: Gender and the (boxing) ring. The Qualitative Report, 17(17), 1- 13.

Messner, M. A., McKay, J., \& Sabo, D. F. (2000). Masculinities, gender relations and sport. Thousand Oaks, CA: Sage. Metcalfe, S. (2018). Adolescent constructions of gendered identities: The role of sport and (physical) education. Sport,

Education and Society, 23(7), 681-693.

Novo, A., \& Elizondo, A. (2010). The social status of men and women in the Basque Country. In M. L. Esteban \& M. Amurrio (Eds.), Feminist challenges in the social sciences. Gender studies in the Basque Country (pp. 11-24). Reno: Center for Basque Studies and University of the Basque Country UPV/EHU. 
Pfister, G. (2010). Women in sport - gender relations and future perspectives. Sport in Society, 13(2), 234-248.

Pope, S. (2014). Female football fans and gender performance. In J. Hargreaves \& E. Anderson (Eds.), Routledge handbook of sport, gender and sexuality (pp. 245-253). London: Routledge.

Ratna, A. (2014). British Asian female footballers: Intersections of identity. In J. Hargreaves \& E. Anderson (Eds.), Routledge handbook of sport, gender and sexuality (pp. 160-168). London: Routledge.

Schep, D. (2012). The limits of performativity: A critique of hegemony in gender theory. Hypatia, 27(4), 864-880.

Scraton, S., \& Flintoff, A. (2002). Sport feminism: The contribution of feminist thought to our understandings of gender and sport. In S. Scraton \& A. Flintoff (Eds.), Gender and sport: A reader (pp. 30-46). London: Routledge.

Sparkes, A., \& Partington, S. (2003). Narrative practice and its potential contribution to sport psychology: The example of

flow. The Sport Psychologist, 17(3), 292-317.

Thorpe, H. (2009). Bourdieu, feminism and female physical culture: Gender reflexivity and the habitus-field complex.

Sociology of Sport Journal, 26(4), 491-516.

Thorpe, H. (2010). Bourdieu, gender reflexivity, and physical culture: A case of masculinities in the snowboarding field.

Journal of Sport \& Social Issues, 34(2), 176-214.

Tredway, K. (2018). Judith Butler, feminism, and the sociology of sport. In L. Mansfield, J. Caudwell, B. Wheaton, \& B. Watson (Eds.), The Palgrave handbook of feminism and sport, leisure and physical education (pp. 409-425). London: Palgrave Macmillan.

Urrutia, J. M., \& Sagastizabal, J. (2009). Erraketistak - Las raquetistas [Basque racket female players]. Durango: Durangoko Arte eta Historia Museoa.

Ussher, J. (1997). Fantasies of femininity: Reforming the boundaries of sex. London: Penguin Books. von der Lippe, G. (2013). Discourses on women's dress codes in beach volleyball and boxing. In G. Pfister \& M. K. Sisjord (Eds.), Gender and sport: Changes and challenges (pp. 140-156). Münster: Waxmann.

Wesely, J. F. (2001). Negotiating gender: Bodybuilding and the natural/unnatural continuum. Sociology of Sport Journal, 18(2), 162-180.

Whitson, D. (2002). The embodiment of gender: Discipline, domination, and empowerment. In S. Scraton \& A. Flintoff (Eds.), Gender and sport: A reader (pp. 227-240). London: Routledge.

With-Nielsen, N., \& Pfister, G. (2011). Gender constructions and negotiations in physical education: Case studies. Sport, Education and Society, 16(5), 645-664. 